\title{
Resveratrol suppresses thyroid hormone-induced osteocalcin synthesis in osteoblasts
}

\author{
KAZUHIKO FUJITA $^{1,2}$, HARUHIKO TOKUDA ${ }^{2,3}$, SHINGO KAINUMA ${ }^{1,2}$, \\ GEN KUROYANAGI $^{1,2}$, NAOHIRO YAMAMOTO ${ }^{1,2}$, RIE MATSUSHIMA-NISHIWAKI ${ }^{2}$, \\ ATSUSHI HARADA ${ }^{4}$, OSAMU KOZAWA ${ }^{2}$ and TAKANOBU OTSUKA ${ }^{1}$
}

\begin{abstract}
${ }^{1}$ Department of Orthopedic Surgery, Nagoya City University Graduate School of Medical Sciences, Nagoya, Aichi 467-8601; ${ }^{2}$ Department of Pharmacology, Gifu University Graduate School of Medicine, Gifu 501-1194; Departments of ${ }^{3}$ Clinical Laboratory and ${ }^{4}$ Orthopedic Surgery, National Center for Geriatrics and Gerontology, Obu, Aichi 474-8511, Japan
\end{abstract}

Received March 31, 2016; Accepted April 4, 2017

DOI: $10.3892 / \mathrm{mmr} .2017 .6872$

\begin{abstract}
Resveratrol, a polyphenolic compound that is present in grape skins, berries and red wine, may be beneficial for human health through its anti-inflammatory and anti-oxidant effects. It has been previously demonstrated that resveratrol exerts its biological effects primarily via sirtuin 1 (SIRT1) activation. We previously reported that triiodothyronine $\left(\mathrm{T}_{3}\right)$ induces osteocalcin synthesis in osteoblast-like MC3T3-E1 cells, and that p38 mitogen-activated protein (MAP) kinase mediates the $\mathrm{T}_{3}$-stimulated synthesis of osteocalcin. The present study investigated the effect of resveratrol on $\mathrm{T}_{3}$-induced osteocalcin synthesis and its underlying mechanism in MC3T3-E1 cells. Cultured cells were stimulated with $\mathrm{T} 3$, and osteocalcin release from MC3T3-E1 cells was measured by ELISA and phosphorylation of p38 MAP kinase was analyzed by western blotting. Resveratrol significantly suppressed the release of osteocalcin stimulated by $\mathrm{T}_{3}$ and SRT1720, a SIRT1 activator, significantly reduced $\mathrm{T}_{3}$-induced osteocalcin release. The expression level of osteocalcin mRNA stimulated by $\mathrm{T}_{3}$ was significantly attenuated by resveratrol and $\mathrm{T}_{3}$-induced transactivation activity of the thyroid hormone-responsive element was significantly diminished by resveratrol. However, only limited effects of resveratrol on the $\mathrm{T}_{3}$-induced phosphorylation of $\mathrm{p} 38$ MAP kinase were observed. The results of the present study demonstrated that resveratrol suppresses $T_{3}$-stimulated osteocalcin synthesis at a point upstream of transcription in osteoblasts, and that the inhibitory effect of resveratrol is mediated, at least partially, through SIRT1 activation. These results indicate that there may be a novel role for the polyphenol in the modulation of bone metabolism.
\end{abstract}

Correspondence to: Dr Haruhiko Tokuda, Department of Clinical Laboratory, National Center for Geriatrics and Gerontology, 7-430 Morioka-cho, Obu, Aichi 474-8511, Japan

E-mail: tokuda@ncgg.go.jp

Key words: resveratrol, triiodothyronine, osteocalcin, osteoblast, mitogen-activated protein kinase

\section{Introduction}

Resveratrol is a natural polyphenolic compound that is present in grapes, berries and red wine. Accumulating evidence indicates that resveratrol may provide various health benefits, including protective properties against cardiovascular disease and cancer $(1,2)$. The majority of the anti-apoptotic or anti-inflammatory effects of resveratrol are associated with the activation of sirtuin 1 (SIRT1), which is known as a nicotinamide adenine dinucleotide $\left(\mathrm{NAD}^{+}\right)$-dependent deacetylase that activates genes associated with longevity and survival $(3,4)$. The French population reportedly tends to consume high levels of saturated fatty acids in their meals however, their circulating levels remain relatively low and they have low mortality rates associated with coronary heart disease, when compared with other countries that have a similar consumption of saturated fats. This may be due to their frequent consumption of red wine containing abundant resveratrol (5).

As for the effects of resveratrol on bone cells, resveratrol is reported to stimulate the differentiation of osteoblasts $(6,7)$, which conduct bone formation and also bone resorption through the expression of receptor activator of nuclear factor- $\mathrm{KB}$ (RANK)-ligand (RANKL), which binds to RANK expressed on osteoclasts (8). Previous reports from this lab have demonstrated that, in osteoblast-like MC3T3-E1 cells, resveratrol suppresses the synthesis of osteoprotegerin (OPG), a decoy receptor of RANKL (8), induced by prostaglandin $\mathrm{F}_{2 \alpha}$ $\left(\mathrm{PGF}_{2 \alpha}\right), \mathrm{PGD}_{2}, \mathrm{PGE}_{1}, \mathrm{PGE}_{2}$ or basic fibroblast growth factor (FGF-2) (9-13). However, resveratrol increases bone morphogenetic protein-4 (BMP-4)-induced OPG synthesis (14). In addition, synthesis of vascular endothelial growth factor (VEGF) induced by BMP-4 or transforming growth factor- $\beta$ (TGF- $\beta$ ) is inhibited by resveratrol in MC3T3-E1 cells $(15,16)$. These findings indicate that resveratrol may orchestrate stimuli from numerous bone remodeling agents, resulting in the modulation of bone metabolism. However, the exact mechanism underlying the effects of resveratrol on osteoblasts remains to be elucidated.

Osteocalcin, which is synthesized in osteoblasts, is the most abundant non-collagenous protein and is also a marker 
of mature osteoblast phenotype (17). Osteocalcin undergoes post-translational modification whereby glutamic acid residues are carboxylated to form $\gamma$-carboxyglutamic acid (Gla) residues by vitamin K-dependent $\gamma$-carboxylase (17). It has been reported that osteocalcin-deficient mice present higher bone mass and bone strength, indicating that osteocalcin is a determining factor in bone formation (18). In addition, it was previously proposed that uncarboxylated osteocalcin released from osteoblasts functions as a hormone, which regulates energy metabolism by stimulation of insulin secretion from pancreatic $\beta$-cells and by upregulation of insulin sensitivity through adiponectin production by adipocytes (19). Thus, the evidence indicates that bone may also have a crucial role as an endocrine organ, regulating energy metabolism through the production of osteocalcin by osteoblasts (20).

In addition to a role in the modulation of whole-body metabolism, thyroid hormone is an important modulator of skeletal function. Excess levels of thyroid hormone, which is termed hyperthyroidism, accelerates metabolic turnover rate and increases the ratio of bone resorption to bone formation, which may lead to osteoporosis $(21,22)$. It was previously reported that bone mineral density is significantly decreased and the risk of fracture increases in untreated patients with hyperthyroidism (23). The thyroid hormone receptor is a member of the steroid hormone receptor superfamily (24). It is established that thyroid hormone, like other steroid hormones, binds to its specific intracellular receptors and the complex subsequently induces the expression of the gene network (24). In our previous study (25), triiodothyronine $\left(\mathrm{T}_{3}\right)$ stimulated osteocalcin synthesis in osteoblast-like MC3T3-E1 cells and p38 mitogen-activated protein (MAP) kinase positively regulated the synthesis. The present study investigated the effect of resveratrol on $\mathrm{T}_{3}$-stimulated osteocalcin synthesis in MC3T3-E1 cells. The results of the present study indicate that resveratrol may suppress $\mathrm{T}_{3}$-stimulated osteocalcin synthesis at a point upstream of transcription in osteoblast-like MC3T3-E1 cells, and that the inhibition by resveratrol is mediated, at least partially, by SIRT1 activation.

\section{Materials and methods}

Materials. $\mathrm{T}_{3}$ was obtained from Sigma-Aldrich; Merck KGaA (Darmstadt, Germany). Resveratrol and SRT1720 were obtained from EMD Millipore (Billerica, MA, USA). The mouse osteocalcin ELISA kit (cat. no. BT-470) was obtained from Alfa Aesar; Thermo Fisher Scientific, Inc. (Lancashire, UK). Phospho-specific p38 MAP kinase (cat. no. \#4511) and p38 MAP kinase (cat. no. \#9212) antibodies were obtained from Cell Signaling Technology, Inc. (Danvers, MA, USA). Glyceraldehyde-3-phosphate dehydrogenase (GAPDH) (cat. no. sc-25778) antibody was purchased from Santa Cruz Biotechnology, Inc. (Dallas, TX, USA). An enhanced chemiluminescence (ECL) western blotting detection system was obtained from GE Healthcare Life Sciences (Chalfont, UK). Other materials and chemicals were obtained from commercial sources. $\mathrm{T}_{3}$ was dissolved in $0.1 \mathrm{M} \mathrm{NaOH}$. Resveratrol and SRT1720 were dissolved in dimethyl sulfoxide. The maximum concentration of dimethyl sulfoxide was $0.1 \%$, which did not affect the assay for osteocalcin, reverse transcription-quantitative polymerase chain reaction (RT-qPCR), luciferase reporter assay or western blot analysis.

Cell culture. Cloned osteoblast-like MC3T3-E1 cells that were derived from newborn mouse calvaria (26) were maintained as previously described (27). Briefly, the cells were cultured in $\alpha$-minimum essential medium ( $\alpha$-MEM) containing $10 \%$ fetal bovine serum (FBS; cat. no. 12483-020; Gibco; Thermo Fisher Scientific, Inc., Waltham, MA, USA) at $37^{\circ} \mathrm{C}$ in a humidified atmosphere of $5 \% \mathrm{CO}_{2} / 95 \%$ air. The cells were seeded into $35 \mathrm{~mm}$ diameter dishes $\left(5 \times 10^{4}\right.$ cells/dish $)$ or $90 \mathrm{~mm}$ diameter dishes $\left(2 \times 10^{5}\right.$ cells/dish) in $\alpha$-MEM containing $10 \%$ FBS. After 5 days, the medium was exchanged for $\alpha$-MEM containing $0.3 \% \mathrm{FBS}$; the cells were used for experiments $48 \mathrm{~h}$ following this exchange.

Assay for osteocalcin. Cultured cells were pretreated with various doses of resveratrol $(0,10,50$ and $70 \mu \mathrm{M})$, or SRT1720 at $37^{\circ} \mathrm{C}$ for $60 \mathrm{~min}$, and subsequently stimulated by $10 \mathrm{nM}$ of $\mathrm{T}_{3}$ or vehicle in $1 \mathrm{ml}$ of $\alpha$-MEM containing $0.3 \% \mathrm{FBS}$ at $37^{\circ} \mathrm{C}$ for 0,48 or $96 \mathrm{~h}$. In the experiment investigating the effect of various resveratrol doses on osteocalcin release, cells were stimulated by $\mathrm{T}_{3}$ or vehicle for $96 \mathrm{~h}$, whereas cells pretreated with SRT170 were stimulated by $\mathrm{T}_{3}$ or vehicle for 0,48 or $96 \mathrm{~h}$. The conditioned medium was collected at the end of incubation and the osteocalcin concentration in the medium was measured using the mouse osteocalcin ELISA kit according to the manufacturer's protocol.

$R T$-qPCR. Cultured cells were pretreated with $50 \mu \mathrm{M}$ of resveratrol or vehicle at $37^{\circ} \mathrm{C}$ for $60 \mathrm{~min}$, and subsequently stimulated by $10 \mathrm{nM}$ of $\mathrm{T}_{3}$ or vehicle in $1 \mathrm{ml}$ of $\alpha$-MEM containing $0.3 \%$ FBS for $48 \mathrm{~h}$. Total RNA was isolated and transcribed into cDNA using TRIzol reagent (Invitrogen; Thermo Fisher Scientific, Inc.) and Omniscript ${ }^{\circledR}$ RT kit (Qiagen, Inc., Valencia, CA, USA), respectively. qPCR was performed using a LightCycler ${ }^{\circledR}$ Fast Start DNA Master SYBR Green I kit in capillaries (Roche Diagnostics, Basel, Switzerland). The forward and reverse primers for mouse osteocalsin mRNA were synthesized based on the reports by Zhang et al (28) and were obtained from Greiner Bio-One Co., Ltd. (Tokyo, Japan). These primer sequences (listed 5'-3') were as follows: forward, TTCTGCTCACTCTGCTGACC and reverse, TTTGTAGGC GGTCTTCAAGC. The forward and reverse primers for mouse GAPDH mRNA were synthesized based on the report by Simpson et al (29) and were obtained from Sigma-Aldrich; Merck KGaA. These primer sequences (listed 5'-3') were as follows: forward, AACGACCCCTTCATTGAC and reverse, TCCACGACATACTCAGCAC. The reaction mixtures were incubated at $95^{\circ} \mathrm{C}$ for $10 \mathrm{~min}$, followed by 40 cycles at $60^{\circ} \mathrm{C}$ for $5 \mathrm{sec}$ and $72^{\circ} \mathrm{C}$ for $7 \mathrm{sec}$. The amplified products were determined by melting curve analysis (30), according to the system protocol. The data were analyzed using the second derivative maximum method and LightCycler3 Data Analysis software (version 3.5.28; Roche Diagnostics). The osteocalcin mRNA levels were normalized to those of GAPDH mRNA using the pfaffl method (31).

Luciferase reporter assay. A reporter plasmid, pDR4 (thyroid hormone-responsive element)-Luc was purchased 


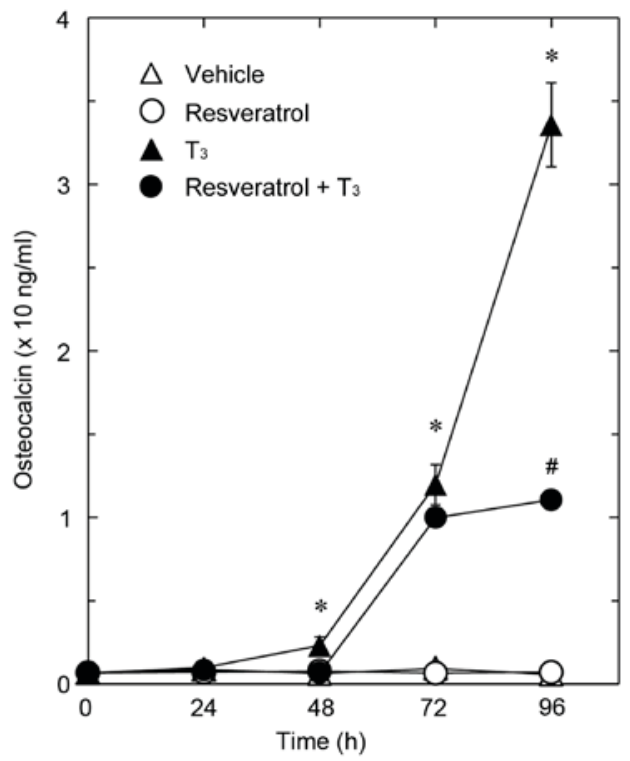

Figure 1. Effect of resveratrol on $\mathrm{T}_{3}$-stimulated osteocalcin release in MC3T3-E1 cells. Cultured cells were pretreated with $50 \mu \mathrm{M}$ of resveratrol $(\bullet, \circ)$ or vehicle $(\boldsymbol{\Lambda}, \Delta)$ for $60 \mathrm{~min}$, and subsequently stimulated with $10 \mathrm{nM}$ of $\mathrm{T}_{3}(\boldsymbol{\bullet}, \mathbf{\Delta})$ or vehicle $(0, \Delta)$ for $0,24,48,72$ or $96 \mathrm{~h}$. Osteocalcin concentrations in the conditioned medium were determined by ELISA. Results are presented as the mean \pm standard error of the mean of triplicate results from three independent cell preparations. ${ }^{*} \mathrm{P}<0.05$ vs. vehicle only and ${ }^{*} \mathrm{P}<0.05$ vs. $\mathrm{T}_{3}$ only. $\mathrm{T}_{3}$, triiodothyronine.

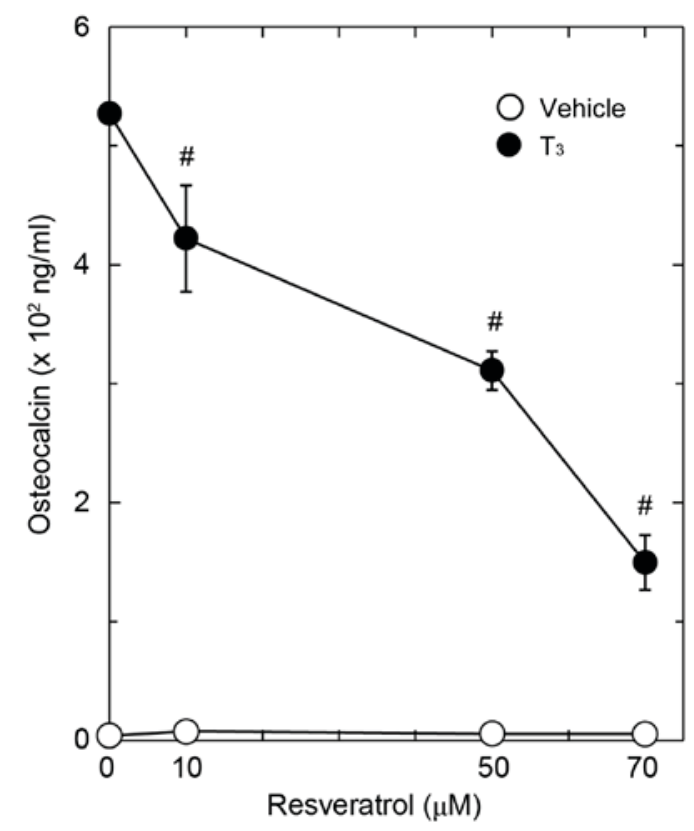

Figure 2. Effect of various doses of resveratrol on $\mathrm{T}_{3}$-stimulated osteocalcin release in MC3T3-E1 cells. Cultured cells were pretreated with various doses of resveratrol for $60 \mathrm{~min}$ and subsequently stimulated with $10 \mathrm{nM}$ of $\mathrm{T}_{3}(\bullet)$ or vehicle (o) for $96 \mathrm{~h}$. Osteocalcin concentrations in the conditioned medium were determined by ELISA. Results are presented as the mean \pm standard error of the mean of triplicate results from three independent cell preparations. ${ }^{\#} \mathrm{P}<0.05$ vs. $\mathrm{T}_{3}$ only. $\mathrm{T}_{3}$, triiodothyronine.

from Stratagene (Agilent Technologies, Inc., Santa Clara, CA, USA). The cultured cells were pretreated with $50 \mu \mathrm{M}$ resveratrol or vehicle at $37^{\circ} \mathrm{C}$ for $6 \mathrm{~h}$ after the transfection with the $p D R 4-L u c$ reporter plasmid (1 $\mu \mathrm{g} / \mathrm{dish}) \mathrm{using}$ UniFector transfection reagent at $37^{\circ} \mathrm{C}$ for $6 \mathrm{~h}$ (B-Bridge International, Inc., Santa Clara, CA, USA). The cells were cotransfected with pRL-CMV (Renilla luciferase; $0.1 \mu \mathrm{g} / \mathrm{dish}$; Promega Corporation, Madison, WI, USA) as an internal standard to normalize transfection efficiency. Following pretreatment, cells were stimulated by $10 \mathrm{nM} \mathrm{T}$ or vehicle at $37^{\circ} \mathrm{C}$ for $48 \mathrm{~h}$. Luciferase activity of the cell lysates was measured using a Dual-Luciferase ${ }^{\circledR}$ Reporter Assay system (Promega Corporation) according to the manufacturer's protocol.

Western blot analysis. The cultured cells were pretreated with various doses of resveratrol $(0,10,30$ and $50 \mu \mathrm{M})$ at $37^{\circ} \mathrm{C}$ for $60 \mathrm{~min}$ and subsequently stimulated by $10 \mathrm{nM}$ of $\mathrm{T}_{3}$ in a-MEM containing $0.3 \% \mathrm{FBS}$ at $37^{\circ} \mathrm{C}$ for $120 \mathrm{~min}$. Cells were washed twice with PBS and lysed, homogenized and sonicated in a lysis buffer containing $62.5 \mathrm{mM}$ Tris/ $\mathrm{HCl}$ (pH 6.8), 2\% SDS, $50 \mathrm{mM}$ dithiothreitol and $10 \%$ glycerol. SDS-PAGE was performed as described by Laemmli (32) on $10 \%$ polyacrylamide gels. Protein quantification was performed using a Pierce Bicinchoninic Acid Protein Assay kit (Thermo Fisher Scientific, Inc.) according to the manufacturer's protocol. Protein (10 $\mu \mathrm{g} /$ lane) was fractionated and transferred onto an Immun-Blot ${ }^{\circledR}$ PVDF membrane (Bio-Rad Laboratories, Inc., Hercules, CA, USA). The membranes were blocked with 5\% fat-free dry milk in TBS-Tween-20 (TBS-T; $20 \mathrm{mM}$ Tris- $\mathrm{HCl}$, $\mathrm{pH} 7.6,137 \mathrm{mM} \mathrm{NaCl}, 0.1 \%$ Tween-20) at $37^{\circ} \mathrm{C}$ for $1 \mathrm{~h}$ prior to incubation with primary antibodies. Western blot analysis was performed as described previously (33) using phospho-specific p38 MAP kinase antibodies, p38 MAP kinase antibodies or GAPDH as primary antibodies, with peroxidase-labeled antibodies raised in goat against rabbit IgG (KPL, Inc., Gaithersburg, MD, USA) used as secondary antibodies. The primary and secondary antibodies were diluted at 1:1,000 with $5 \%$ fat-free dry milk in TBS-T. The peroxidase activity on the PVDF sheet was visualized on X-ray film by means of the ECL western blotting detection system (GE Healthcare Life Sciences) according to the manufacturer's protocol.

Statistical analysis. Results were analyzed by one-way analysis of variance followed by the Bonferroni method for multiple comparisons between pairs, using Microsoft Office Excel 2013 for Windows (Microsoft Corporation, Redmond, WA, USA) and $\mathrm{P}<0.05$ was considered to indicate a statistically significant difference. Results are presented as the mean \pm standard error of the mean of triplicate results from three independent cell preparations.

\section{Results}

Effect of resveratrol on the $T_{3}$-stimulated osteocalcin release in MC3T3-E1 cells. The present study first investigated the effect of resveratrol on $\mathrm{T}_{3}$-stimulated osteocalcin release in osteoblast-like MC3T3-E1 cells. As previously described (25), $\mathrm{T}_{3}$ stimulated secretion of osteocalcin after $48 \mathrm{~h}$. Resveratrol, which had a limited effect on the release of osteocalcin alone, significantly reduced $\mathrm{T}_{3}$-stimulated release of osteocalcin compared with cells treated with $\mathrm{T}_{3}$ only (Fig. 1). The suppressive effect of resveratrol on the $\mathrm{T}_{3}$-stimulated osteocalcin release was dose-dependent in the range between 10 and $70 \mu \mathrm{M}$ (Fig. 2). The maximum effect of resveratrol was 
observed at $70 \mathrm{mM}$, which caused a $\sim 70 \%$ decrease in the $\mathrm{T}_{3}$-effect.

Effect of SRT1720 on the $T_{3}$-stimulated osteocalcin release in MC3T3-E1 cells. It has been previously reported that resveratrol exerts its biological effects through the activation of SIRT1 $(1,2)$. Thus, the present study investigated the effect of SRT1720, which is a specific and potent synthetic activator of SIRT1 (34), on $\mathrm{T}_{3 \text { - }}$ stimulated osteocalcin release in osteoblast-like MC3T3-E1 cells. Similarly to resveratrol, SRT1720 significantly reduced $\mathrm{T}_{3}$-stimulated osteocalcin synthesis compared with cells treated with $\mathrm{T}_{3}$ only (Fig. 3).

Effect of resveratrol on $T_{3}$-induced expression of osteocalcin mRNA in MC3T3-E1 cells. In order to investigate whether the inhibitory effect of resveratrol on the $\mathrm{T}_{3}$-stimulated osteocalcin release is exerted through transcriptional events or not, the present study examined the effect of resveratrol on $\mathrm{T}_{3}$-induced osteocalcin mRNA expression by RT-qPCR. Resveratrol, which had no effect on basal levels of osteocalcin mRNA when applied alone, significantly reduced the expression level of osteocalcin mRNA induced by $\mathrm{T}_{3}$ compared with cells treated with $\mathrm{T}_{3}$ only (Fig. 4).

Effect of resveratrol on $T_{3}$-induced transactivation activity of thyroid hormone-responsive element in MC3T3-E1 cells. In addition, the effect of resveratrol on $\mathrm{T}_{3}$-stimulated transactivation activity of thyroid hormone-responsive element in osteoblast-like MC3T3-E1 cells was investigated using a luciferase reporter assay. Pretreatment with resveratrol alone had a limited effect on the luciferase activity of thyroid hormone-responsive element compared with untreated cells (Fig. 5). However, resveratrol significantly inhibited the activity induced by $\mathrm{T}_{3}$ compared with cells treated with $\mathrm{T}_{3}$ only (Fig. 5).

Effect of resveratrol on the $T_{3}$-induced phosphorylation of p38 MAP kinase in MC3T3-E1 cells. In our previous study, $\mathrm{T}_{3}$-stimulated osteocalcin synthesis was demonstrated to be positively regulated through the p38 MAP kinase pathway in osteoblast-like MC3T3-E1 cells (25). In order to clarify whether the activation of $\mathrm{p} 38$ MAP kinase is implicated in the resveratrol-effect on $\mathrm{T}_{3}$-induced osteocalcin synthesis in these cells, the present study investigated the effect of resveratrol on the $\mathrm{T}_{3}$-induced phosphorylation of $\mathrm{p} 38$ MAP kinase. However, the results demonstrated that resveratrol did not affect the $\mathrm{T}_{3}$-stimulated phosphorylation of p38 MAP kinase (Fig. 6).

\section{Discussion}

The present study demonstrated that resveratrol significantly decreased $\mathrm{T}_{3}$-stimulated osteocalcin release in osteoblast-like MC3T3-E1 cells. Additionally, it was observed that resveratrol significantly reduced osteocalcin mRNA levels upregulated by $T_{3}$. Therefore, the inhibitory effect of resveratrol on the $\mathrm{T}_{3}$-induced osteocalcin synthesis may occur upstream of transcriptional levels in osteoblast-like MC3T3-E1 cells. A number of biological effects of resveratrol are reported to be dependent on SIRT1 activation $(1,2)$. Therefore, in order to investigate whether the suppression of $\mathrm{T}_{3}$-stimulated osteocalcin synthesis

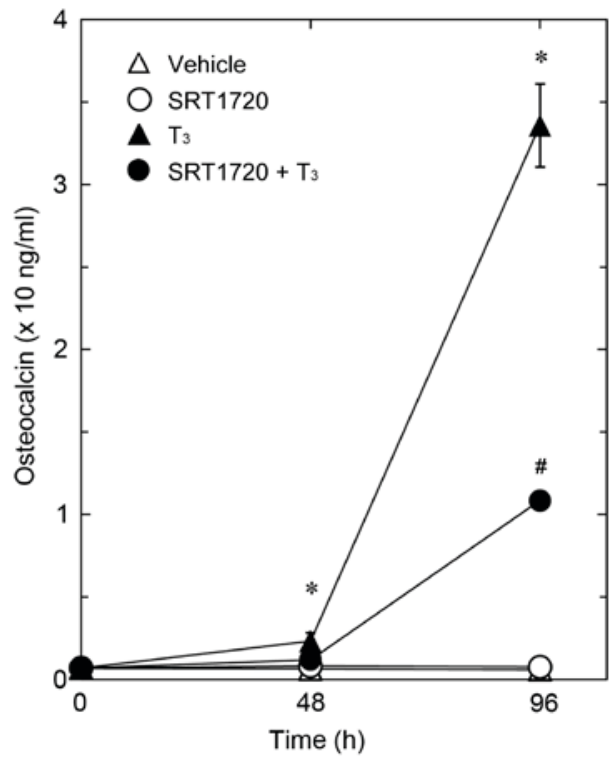

Figure 3. Effect of SRT1720 on $\mathrm{T}_{3}$-stimulated osteocalcin release in MC3T3-E1 cells. Cultured cells were pretreated with $10 \mu \mathrm{M}$ of SRT1720 $(\bullet, \circ)$ or vehicle $(\boldsymbol{\Delta}, \Delta)$ for $60 \mathrm{~min}$, and subsequently stimulated with $10 \mathrm{nM}$ of $\mathrm{T}_{3}(\bullet, \boldsymbol{\Delta})$ or vehicle $(\circ, \Delta)$ for 0,48 or $96 \mathrm{~h}$. Osteocalcin concentrations in the conditioned medium were determined by ELISA. Results are presented as the mean \pm standard error of the mean of triplicate results from three independent cell preparations. ${ }^{*} \mathrm{P}<0.05$ vs. vehicle only and ${ }^{\#} \mathrm{P}<0.05$ vs. $\mathrm{T}_{3}$ only. $\mathrm{T}_{3}$, triiodothyronine.

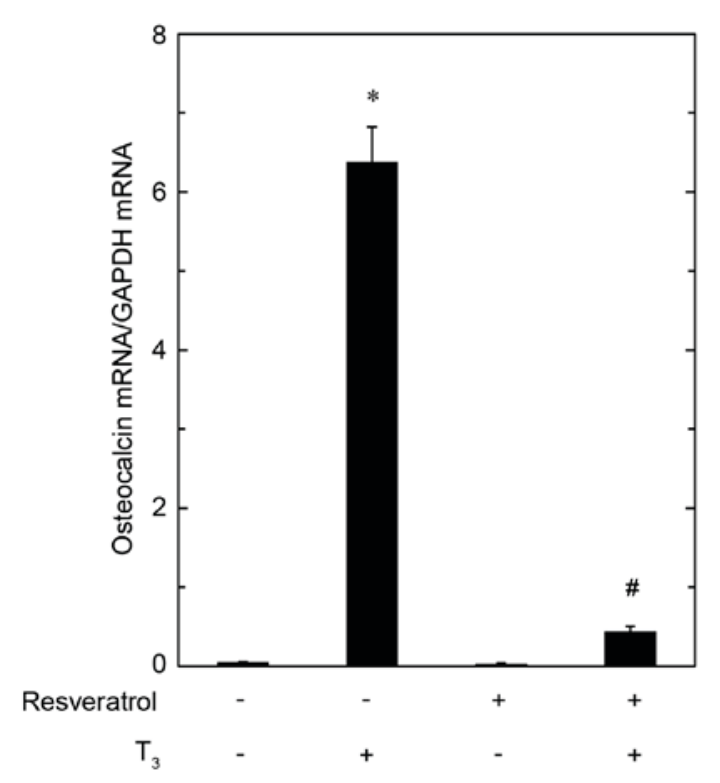

Figure 4. Effect of resveratrol on $\mathrm{T}_{3}$-induced expression levels of osteocalcin mRNA in MC3T3-E1 cells. Cultured cells were pretreated with $50 \mu \mathrm{M}$ of resveratrol or vehicle for $60 \mathrm{~min}$, and subsequently stimulated with $10 \mathrm{nM}$ of $\mathrm{T}_{3}$ or vehicle for $48 \mathrm{~h}$. The expression of osteocalcin mRNA and GAPDH mRNA were quantified by reverse transcription-quantitative polymerase chain reaction and osteocalcin mRNA levels were normalized to GAPDH mRNA levels. Results are presented as the mean + standard error of the mean of triplicate results from three independent cell preparations. ${ }^{*} \mathrm{P}<0.05$ vs. control and ${ }^{\#} \mathrm{P}<0.05$ vs. $\mathrm{T}_{3}$ only. $\mathrm{T}_{3}$, triiodothyronine.

by resveratrol is mediated through SIRT1 in MC3T3-E1 cells, the effect of SRT1720, a synthetic compound that activates SIRT1 with a potency 1,000-fold greater than resveratrol (34), on the release of osteocalcin was examined. The results 


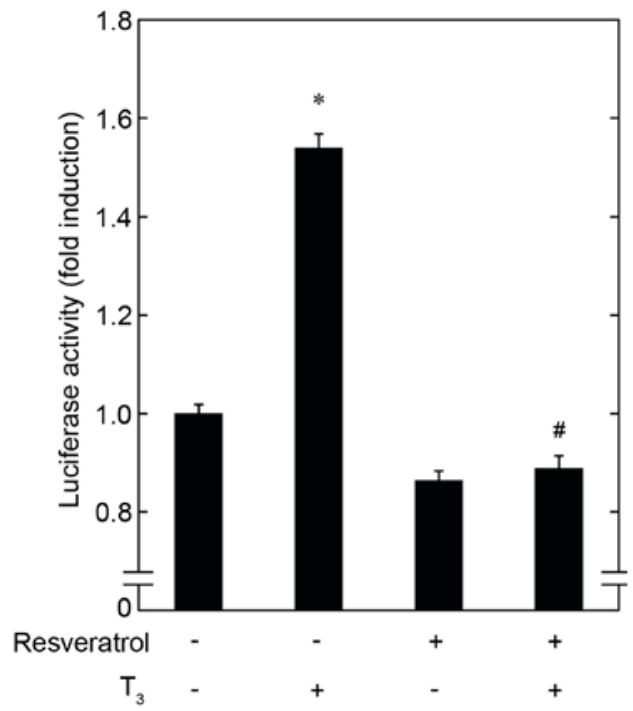

Figure 5. Effect of resveratrol on $\mathrm{T}_{3}$-induced transactivation activity of thyroid hormone-responsive element in MC3T3-E1 cells. Cultured cells were pretreated with $50 \mu \mathrm{M}$ resveratrol or vehicle at $6 \mathrm{~h}$ after transfection with the pDR4-Luc reporter plasmid ( $1 \mu \mathrm{g} / \mathrm{dish})$. Following the pretreatment for $60 \mathrm{~min}$, cells were stimulated with $10 \mathrm{nM} \mathrm{T}_{3}$ or vehicle for $48 \mathrm{~h}$. A luciferase reporter assay was conducted. Values are presented as fold induction of luciferase activity compared with the control and as the mean \pm standard error of the mean of triplicate results from three independent cell preparations. ${ }^{*} \mathrm{P}<0.05$ vs. vehicle only and ${ }^{\#} \mathrm{P}<0.05$ vs. $\mathrm{T}_{3}$ only. $\mathrm{T}_{3}$, triiodothyronine.

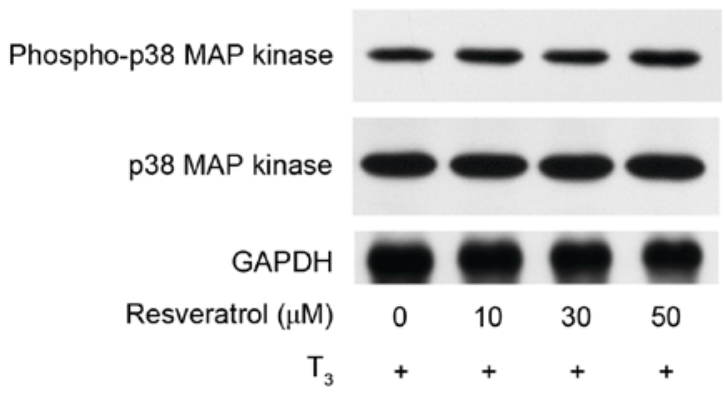

Figure 6. Effect of resveratrol on $\mathrm{T}_{3}$-induced phosphorylation of $\mathrm{p} 38$ MAP kinase in MC3T3-E1 cells. Cultured cells were pretreated with 0, 10, 30 or $50 \mu \mathrm{M}$ resveratrol for $60 \mathrm{~min}$, and subsequently stimulated with $10 \mathrm{nM}$ of $\mathrm{T}_{3}$ for $120 \mathrm{~min}$. Cell extracts were subjected to SDS-PAGE, with subsequent western blot analysis with antibodies against phospho-specific p38 MAP kinase, p38 MAP kinase, or GAPDH. $\mathrm{T}_{3}$, triiodothyronine; MAP kinase, mitogen activated protein kinase.

demonstrated that SRT1720 mimicked the suppressive effect of resveratrol on $\mathrm{T}_{3}$-induced release of osteocalcin. Based on the results, the inhibitory effect of resveratrol on osteocalcin synthesis induced by $\mathrm{T}_{3}$ may be mediated, at least partially, by the activation of SIRT1 in osteoblast-like MC3T3-E1 cells.

It is established that the effects of thyroid hormone, a member of the nuclear receptor superfamily, are exerted via its binding to specific receptors in the nucleus, and that the receptor-hormone complex subsequently activates target gene expression (35). Therefore, the present study investigated the effect of resveratrol on $\mathrm{T}_{3}$-induced transactivation activity of thyroid hormone-responsive element by a luciferase reporter assay in MC3T3-E1 cells. Resveratrol significantly reduced the $\mathrm{T}_{3}$-induced transactivation activity of thyroid hormone-responsive element, in addition to the expression of osteocalcin mRNA in MC3T3-E1 cells. The results indicate that the inhibitory effect of resveratrol on $\mathrm{T}_{3}$-induced osteocalcin synthesis may be exerted upstream of gene transcription in osteoblast-like MC3T3-E1 cells.

In the MAP kinase superfamily, it is established that p44/p42 MAP kinase, p38 MAP kinase and stress-activated protein kinase/c-Jun $\mathrm{N}$-terminal kinase have pivotal roles in a variety of cellular functions, including proliferation, differentiation and survival (36). Our previous studies $(25,37)$ reported that $\mathrm{T}_{3}$ stimulates the activation of $\mathrm{p} 44 / \mathrm{p} 42$ MAP kinase and p38 MAP kinase in osteoblast-like MC3T3-E1 cells, and that p38 MAP kinase, and not p44/p42 MAP kinase, functions as a positive regulator in osteocalcin synthesis stimulated by $\mathrm{T}_{3}$. However, the present study demonstrated that resveratrol did not affect the $\mathrm{T}_{3}$-induced phosphorylation of p38 MAP kinase in these cells. Based on the results, it seems unlikely that the effect of resveratrol on $\mathrm{T}_{3}$-stimulated osteocalcin synthesis is exerted at a point upstream of p38 MAP kinase in osteoblast-like MC3T3-E1 cells.

Osteocalcin is synthesized specifically in mature osteoblasts and stored in the bone matrix (17). The presence of the three Gla residues is critical for the structure and function of osteocalcin, which allows it to bind to hydroxyapatite with a high affinity in their fully carboxylated state, which subsequently regulates the maintenance of adequate bone mass (18). Therefore, the results of the present study, which demonstrate suppression of $\mathrm{T}_{3}$-stimulated osteocalcin synthesis by resveratrol, may indicate a novel role for the polyphenol in the modulation of bone metabolism. We have recently demonstrated that resveratrol modulates the synthesis of OPG stimulated by $\mathrm{PGF}_{2 \alpha}, \mathrm{PGD}_{2}, \mathrm{PGE}_{1}, \mathrm{PGE}_{2}, \mathrm{FGF}-2$ or BMP-4, and regulates VEGF synthesis induced by BMP-4 or TGF- $\beta$ in osteoblast-like MC3T3-E1 cells (9-16). Taking these findings into account, resveratrol may support the maintenance of skeletal conditions via orchestrating osteoblast functions elicited by various stimuli, including prostaglandins, cytokines and growth factors, which may explain the lower hip bone fracture risk observed in wine drinkers (6). In addition, osteocalcin has recently been recognized as a potent bone-derived hormone that regulates energy or lipid metabolism (20). Based on the results of the current study, as $\mathrm{T}_{3}$-stimulated osteocalcin synthesis was suppressed by resveratrol in osteoblast-like MC3T3-E1 cells, resveratrol may modulate whole body energy metabolism through the regulation of osteocalcin synthesis in osteoblasts. Further investigation is required to clarify the exact mechanism underlying the effects of resveratrol in osteoblasts. In conclusion, the results of the present study indicate that resveratrol suppresses $\mathrm{T}_{3}$-stimulated osteocalcin synthesis upstream of transcription in osteoblasts, and that the inhibitory effect of resveratrol is partially mediated by SIRT1.

\section{Acknowledgements}

We are grateful to Mrs. Yumiko Kurokawa (Department of Pharmacology, Gifu University Graduate School of Medicine, Gifu, Japan) for her excellent technical assistance. The present study was supported in part by a Grant-in-Aid for Scientific Research (grant no. 19591042) from the Ministry of Education, Culture, Sports, Science and Technology of Japan, a Grant-in-Aid for Scientific Research (grant no. H25-Aging-General-004) 
from the Ministry of Health, Labour and Welfare of Japan, and the Research Funding for Longevity Sciences (grant no. 25-4, 26-12) from National Center for Geriatrics and Gerontology (Obu, Japan).

\section{References}

1. Blander G and Guarente L: The Sir2 family of protein deacetylases. Annu Rev Biochem 73: 417-435, 2004.

2. Koo SH and Montminy M: In vino veritas: A tale of two Sirt1s? Cell 127: 1091-1093, 2006.

3. Howitz KT, Bitterman KJ, Cohen HY, Lamming DW, Lavu S, Wood JG, Zipkin RE, Chung P, Kisielewski A, Zhang LL, et al: Small molecule activators of sirtuins extend Saccharomyces cerevisiae lifespan. Nature 425: 191-196, 2003

4. Baur JA, Pearson KJ, Price NL, Jamieson HA, Lerin C, Kalra A, Prabhu VV, Allard JS, Lopez-Lluch G, Lewis K, et al: Resveratrol improves health and survival of mice on a high-calorie diet. Nature 444: 337-342, 2006.

5. Biagi M and Bertelli AA: Wine, alcohol and pills: What future for the French paradox? Life Sci 131: 19-22, 2015.

6. Kubo JT, Stefanick ML, Robbins J, Wactawski-Wende J, Cullen MR, Freiberg M and Desai M: Preference for wine is associated with lower hip fracture incidence in post-menopausal women. BMC Women's Health 13: 36, 2013.

7. Mizutani K, Ikeda K, Kawai Y and Yamori Y: Resveratrol stimulates the proliferation and differentiation of osteoblastic MC3T3-E1 cells. Biochem Biophys Res Commun 253: 859-863, 1998.

8. Suda T, Takahashi N, Udagawa N, Jimi E, Gillespie MT and Martin TJ: Modulation of osteoclast differentiation and function by the new members of the tumor necrosis factor receptor and ligand families. Endocr Rev 20: 345-357, 1999.

9. Kuroyanagi G, Tokuda H, Matsushima-Nishiwaki R, Kondo A, Mizutani J, Kozawa O and Otsuka T: Resveratrol suppresses prostaglandin $\mathrm{F}(2 \alpha)$-induced osteoprotegerin synthesis in osteoblasts: Inhibition of the MAP kinase signaling. Arch Biochem Biophys 542: 39-45, 2014

10. Kuroyanagi G, Mizutani J, Kondo A, Yamamoto N, Matsushima-Nishiwaki R, Otsuka T, Kozawa O and Tokuda $\mathrm{H}$ Suppression by resveratrol of prostaglandin D2-stimulated osteoprotegerin synthesis in osteoblasts. Prostaglandins Leukot Essent Fatty Acids 91: 73-80, 2014.

11. Yamamoto N, Otsuka T, Kuroyanagi G, Kondo A, Kainuma S, Nakakami A, Matsushima-Nishiwaki R, Kozawa O and Tokuda H: Resveratrol reduces prostaglandin E1-stimulated osteoprotegerin synthesis in osteoblasts: Suppression of stress-activated protein kinase/c-Jun N-terminal kinase. Prostaglandins Other Lipid Mediat 116-117: 57-63, 2015.

12. Yamamoto $\mathrm{N}$, Tokuda $\mathrm{H}$, Kuroyanagi G, Mizutani J, Matsushima-Nishiwaki R, Kondo A, Kozawa O and Otsuka T: Regulation by resveratrol of prostaglandin E2-stimulated osteoprotegerin synthesis in osteoblasts. Int J Mol Med 34: 1439-1445, 2014.

13. Kuroyanagi G, Otsuka T, Yamamoto N, Matsushima-Nishiwaki R, Nakakami A, Mizutani J, Kozawa O and Tokuda H: Down-regulation by resveratrol of basic fibroblast growth factor-stimulated osteoprotegerin synthesis through suppression of Akt in osteoblasts. Int J Mol Sci 15: 17886-17900, 2014.

14. KuroyanagiG,TokudaH,YamamotoN,Matsushima-NishiwakiR, Mizutani J, Kozawa O and Otsuka T: Resveratrol amplifies BMP-4-stimulated osteoprotegerin synthesis via p38 MAP kinase in osteoblasts. Mol Med Rep 12: 3849-3854, 2015.

15. Kondo A, Otsuka T, Kuroyanagi G, Yamamoto $\mathrm{N}$ Matsushima-Nishiwaki R, Mizutani J, Kozawa $\mathrm{O}$ and Tokuda H: Resveratrol inhibits BMP-4-stimulated VEGF synthesis in osteoblasts: Suppression of S6 kinase. Int J Mol Med 33: 1013-1018, 2014.
16. Kuroyanagi G, Otsuka T, Yamamoto N,Matsushima-Nishiwaki R, Kozawa $\mathrm{O}$ and Tokuda H: Resveratrol suppresses TGF- $\beta$-induced VEGF synthesis in osteoblasts: Inhibition of the p44/p42 MAPKs and SAPK/JNK pathways. Exp Ther Med 9: 2303-2310, 2015.

17. Hauschka PV, Lian JB, Cole DE and Gundberg CM: Osteocalcin and matrix Gla protein: Vitamin K-dependent proteins in bone. Physiol Rev 69: 990-1047, 1989.

18. Ducy P, Desbois C, Boyce B, Pinero G, Story B, Dunstan C, Smith E, Bonadio J, Goldstein S, Gundberg C, et al: Increased bone formation in osteocalcin-deficient mice. Nature 382 : 448-452, 1996

19. Lee NK and Karsentry G: Reciprocal regulation of bone and energy metabolism. Trends Endocrinol Metab 19: 161-166, 2008.

20. Oldknow KJ, MacRae VE and Farquharson C: Endocrine role of bone: Recent and emerging perspectives beyond osteocalcin. J Endocrinol 225: R1-R19, 2015

21. Gogakos AI, Duncan Bassett JH and Williams GR: Thyroid and bone. Arch Biochem Biophys 503: 129-136, 2010.

22. Gorka J, Taylor-Gjevre RM and Arnason T: Metabolic and clinical consequences of hyperthyroidism on bone density. Int J Endocrinol 2013: 638727, 2013.

23. Vestergaard P and Mosekilde L: Hyperthyroidism, bone mineral, and fracture risk-a meta-analysis. Thyroid 13: 585-593, 2003.

24. Cheng SY, Leonard JL and Davis PJ: Molecular aspects of thyroid hormone actions. Endocr Rev 31: 139-170, 2010.

25. Ishisaki A, Tokuda H, Yoshida M, Hirade K, Kunieda K, Hatakeyama D, Shibata T and Kozawa O: Activation of p38 mitogen-activated protein kinase mediates thyroid hormone-stimulated osteocalcin synthesis in osteoblasts. Mol Cell Endocrinol 214: 189-195, 2004.

26. Sudo H, Kodama HA, Amagai Y, Yamamoto S and Kasai S: In vitro differentiation and calcification in a new clonal osteogenic cell line derived from newborn mouse calvaria. J Cell Biol 96: 191-198, 1983.

27. Kozawa O, Tokuda H, Miwa M, Kotoyori J and Oiso Y: Cross-talk regulation between cyclic AMP production and phosphoinositide hydrolysis induced by prostaglandin E2 in osteoblast-like cells. Exp Cell Res 198: 130-134, 1992.

28. Zhang W, Yang N and Shi XM: Regulation of mesenchymal stem cell osteogenic differentiation by glucocorticoid-induced leucine zipper (GILZ). J Biol Chem 283: 4723-4729, 2008.

29. Simpson DA, Feeney S, Boyle C and Stitt AW: Retinal VEGF mRNA measured by SYBR Green I fluorescence: A versatile approach to quantitative PCR. Mol Vis 6: 178-183, 2000.

30. Pryor RJ and Wittwer CT: Real-time polymerase chain reaction and melting curve analysis. Methods Mol Biol 336: 19-32, 2006.

31. Pfaffl MW: A new mathematical model for relative quantification in real-time RT-PCR. Nucleic Acids Res 29: e45, 2001.

32. Laemmli UK: Cleavage of structural proteins during the assembly of the head of bacteriophage T4. Nature 227: 680-685, 1970.

33. Kato K, Ito $\mathrm{H}$, Hasegawa $\mathrm{K}$, Inaguma $\mathrm{Y}$, Kozawa $\mathrm{O}$ and Asano T: Modulation of the stress-induced synthesis of hsp27 and alpha B-crystallin by cyclic AMP in C6 rat glioma cells. J Neurochem 66: 946-950, 1996.

34. Milne JC, Lambert PD, Schenk S, Carney DP, Smith JJ, Gagne DJ, Jin L, Boss O, Perni RB, Vu CB, et al: Small molecule activators of SIRT1 as therapeutics for the treatment of type 2 diabetes. Nature 450: 712-716, 2007.

35. Mullur R, Liu YY and Brent GA: Thyroid hormone regulation of metabolism. Physiol Rev 94: 355-382, 2014.

36. Kyriakis JM and Avruch J: Mammalian mitogen-activated protein kinase signal transduction pathways activated by stress and inflammation. Physiol Rev 81: 807-869, 2001.

37. Kozawa O, Hatakeyama D, Yoshida M, Kamiya Y, Kondo C, Matsuno H and Uematsu T: Activation of p44/p42 mitogen-activated protein kinase limits triiodothyronine-stimulated alkaline phosphatase activity in osteoblasts. Biochem Biophys Res Commun 286: 1140-1143, 2001. 